\title{
Maria Susanna CUMmins e Rosalía de CASTRO
}

\author{
KathleEn N. March \\ University of Maine
}

Resumo: Estudo comparado de The Lamplighter (i854), da escritora norteamericana Maria Susanna Cummins, e La hija del mar (I859), da escritora galega Rosalía de Castro, que pon en cuestión a recepción tópica da chamada literatura sentimental. Establécense paralelismos tanto entre as autoras como entre as protagonistas das novelas, e préstase especial atención aos condicionantes de xénero en relación á clase social, as posibilidades profesionais das mulleres do seu tempo e como se conceptúa a idea do fogar en relación á nación. Palabras chave: Maria Susanna Cummins, Rosalía de Castro, narradoras do século XIX.

\section{Maria Susanna Cummins and Rosalía de Castro}

Aвstract: The present article is a comparative study of The Lamplighter (1854), by the North American author Maria Susanna Cummins, and La hija del mar (1859) by the Galician author Rosalía de Castro, which questions the reception of the so-called sentimental literature. Parallels are established not only between the authors, but also between the protagonists of the novels, and special attention is paid to gender conditions related to social class, professional possibilities for the women of their time and for the way in which the idea of the home is conceptualized in relation to that of the nation.

Keywords: Maria Susanna Cummins, Rosalía de Castro, $19^{\text {th }}$ century women writers

O obxectivo deste traballo é comparar dúas escritoras do século XIX: Rosalía de Castro e Maria Susanna Cummins, coa advertencia de que só podemos basearnos directamente nos dous epígrafes da norteamericana que figuran, en francés, na primeira novela rosaliana, La hija del mar, publicada en I859. Xa que logo, non dispomos dunha base comparativa moi grande e dende a perspectiva estritamente textual, non ofrece moita información. Non obstante, precisamente por seren Castro e Cummins mulleres do século XIX, moi afastadas unha da outra no espazo e pasando polo francés —lingua que non era a primeira de Rosalía nin de Cummins - cómpre axustar a nosa comparación ao contexto. 
Limitármonos aos textos suporía esquecer o que eran as experiencias das literatas nese século, e non só nas semellanzas desa experiencia senón tamén nas diferenzas. Expliquémonos: igual que non eran iguais os homes e as mulleres que escribían, tampouco as mulleres traballaban en contextos culturais similares mais dalgún xeito formaban unha comunidade baseada no seu sexo. Nesta comunidade xuntábanse mulleres de diversas clases, relixións e formacións intelectuais nunha conciencia de que o sexo feminino non ocupaba o mesmo posto na sociedade que ocupaba o home. No xIx houbo un gran desenvolvemento sobre como pensaban as mulleres aquela diferenza.

Cummins naceu en Salem, Massachusetts, en i827 e morreu en i866 no mesmo estado, polo que foi contemporánea de Rosalía. Publicou a súa primeira novela, The Lamplighter, o I de marzo de I854, aos 27 anos. Seguiríana cinco libros máis en dez anos. É ben sabido que nos Estados Unidos o éxito desa novela, The Lamplighter, foi tanto que o mestre de literatura norteamericana Nathaniel Hawthorne (1804-1864) protestaría nunha carta moi soada sobre a cantidade de "mulleres escribidoras". ${ }^{1}$ Xa en 1975 a importancia da carta subliñábaa o crítico John Frederick (i975) e lembraríase moitas veces (cf. Voloshin I984 e Wallace i99o) até hoxe en día.

Cómpre lembrarmos que no XIX a comunidade literaria estadounidense se centraba principalmente no leste e, máis aínda, en Nova Inglaterra, polo que podían ter contacto os que producían e os que consumían literatura. Os escritores, a pesar de viviren nun país en expansión, habitaban unha zona xeográfica relativamente reducida, cunha lingua e con moitos contactos persoais e familiares por mor dos xornais, revistas, faladoiros e charlas organizadas por diversos grupos, xunto coas librerías e bibliotecas. Cummins, dende logo, non vivía na periferia, senón que, estando non lonxe de Boston, estaba no centro das actividades culturais. Ela e outras escritoras si que tiñan mentores, bibliotecas, librerías e outros recursos para desenvolveren as súas aspiracións literarias, malia non teren aceso á universidade. Aínda así, pola carraxe dun Hawthorne, patriarca do mundo da escrita xunto con Melville, Longfellow e outros homes, e pola experiencias doutras mulleres daquel tempo, sabemos que a participa-

${ }^{1}$ Nunha carta ao seu editor, William Ticknor, escrita en xaneiro de I855 dende Inglaterra, di: «America is now wholly given over to a damned mob of scribbling women, and I should have no chance of success while the public taste is occupied with their trash — and should be ashamed of myself if I did succeed. What is the mystery of these innumerable editions of the Lamplighter, and other books neither better nor worse? - worse they could not be, and better they need not be, when they sell by the 100,000» (cit. en Baym 1994: 4). 
ción feminina non era sempre fácil. As oportunidades existían, si, mais non sempre se atopaban con facilidade.

Subliñamos o éxito de vendas de The Lamplighter, na súa primeira edición americana, ${ }^{2}$ que axiña iría acompañada da publicación repetida en Inglaterra e da case inmediata tradución ao francés. Foi nesta última lingua, como xa dixemos, como se fixo accesíbel a novela á nova lectora galega. O éxito fora inmediato: vinte mil exemplares vendidos en menos dun mes, 40 mil en dous meses, 65 mil en cinco meses. Unicamente A cabana do Tío Tom, coñecidísima novela publicada dous anos antes, tivera máis éxito.

Se só queremos engadir a presenza das protagonistas femininas - Gertie e Emily, Esperanza e Teresa - en ambas as dúas novelas, cada unha delas criada por persoas que non son da súa familia e retratadas cun discurso aparentemente sentimental ou romántico, xa teremos rematada a tarefa. Mais iso non sería máis que repetir o que se cría e se dicía antes de Rosalía, sería insistirmos no obvio: o feito de ela terse preocupado polas vidas difíciles dunhas mulleres. Por certa que fose esta observación, non ten en conta a forza e a amplitude do pensamento da literata galega nin a verdadeira forza do sentimentalismo literario no seu momento como recurso empregado polas mulleres para expresaren ideas non gratas aos Hawthorne de todos os países. Falamos de forza porque Rosalía cuestionaba o papel e os dereitos da muller na sociedade, non dende a perspectiva dun deber «feminino», senón coa completa confianza na igualdade das mulleres, especialmente da igualdade das galegas, que eran participantes activas na economía e eran capaces de se sosteren soas (como Teresa e Esperanza). A relación entre Teresa e o home ausente non é problemática pola situación económica dela, senón pola soidade afectiva. Non é unha muller débil, só está triste porque non está acompañada: non ten nin home nin fillo. Aínda así, ten a filla adoptiva, Esperanza, quen veu encher un baleiro sentimental moi grande na vida de Teresa.

En primeiro lugar, o contexto norteamericano non era igual ao europeo e ibérico polas oportunidades que ofrecía o primeiro. As norteamericanas podían e debían estudar, e iso a miúdo ocorría porque os pais de varias das escritoras eran pastores protestantes que apoiaban o feito de estudaren as fillas literatura, linguas (inclusive as clásicas) e outras disciplinas. Nunha palabra, as letras non lles eran nin vedadas nin descoñecidas; lían, escribían, publicaban, aínda que non tivesen dereito a acceder a todos os eidos profesionais que

\footnotetext{
${ }^{2}$ Publicouse en Boston: John P. Jewett \& Company, I854.
} 
tiñan os homes. Como observa unha das críticas norteamericanas máis importantes:

Whether conservative, liberal, radical, or moderate on any particular issue, however, nineteenth-century American women seem to have concurred that no matter what strictures barred women from activity in various walks of public life, and no matter whether these strictures were fair or unjust, print was one domain that had long since been opened to them. (Baym 1998: 336)

Moito temos escoitado falar do culto ao fogar e da virtude como cousa particularmente necesaria para rapazas e mulleres ou para «as futuras nais». Porén, malia a tradicional separación en espazos interiores ou privados como femininos e en espazos exteriores ou públicos como masculinos, pode que esta interpretación dos costumes e das crenzas non sexa axeitada — e iso que a vén repetindo a crítica feminista até agora (cf. Kelley 200I).

¿Por que se van afastar as norteamericanas das anglosaxonas da figura do anxo do fogar, popularizado no poema de Coventry Patmore («The Angel of the House», I854, revisado en I862)? É unha pregunta fundamental que axudará a explicarmos como comezaban a mudar as aspiracións femininas nuns países e como non se acadaría o mesmo nivel de desenvolvemento na mesma época noutros. O suposto «anxo» non se atopaba, dende logo, en todos os niveis sociais:

The primary reference group for Victorian (and modern) discussions of the Victorian angel in the house is, I suggest, the women of the upper-middle class - the wives and daughters of clergymen, country gentlemen, and prosperous and wellborn men in the professions and business. If any woman carried out the religious and social mandates of the angel model, it was the gentlewoman. (Peterson 200I: $678)$

Unha das explicacións deste reaxuste de perspectiva para explicar a importancia do «mundo íntimo» para os homes e para as mulleres vén da reformulación por parte da crítica do que entendemos por sentimentalismo. Nesta revisión do concepto establécese que o sentimental pode ter dúas posibilidades de significado. Tamén, como subliñan diversos críticos, o sentimentalismo non só é visto de maneira favorábel polos escritores e polas escritoras. E tamén é rexeitado como clasificación para algunhas das obras que anteriormente pareceran esaxeradamente cheas de bágoas e superficiais. Inclusive, sospeita 
Nina Baym (1998: 336), «perhaps women's novels — even women’s domestic novels - are less sentimental than we have supposed».

Nun país novo como os Estados Unidos, pensábase que o proxecto de construir a nación requiría o labor de ambos os dous sexos. Xa que logo, a relixión protestante esixía a virtude na muller, que ocupaba o seo da familia, mais ser nai tiña unha función importante, a de criar fillos para a «familia nacional», para que fose forte e capaz de cumprir o Destino Manifesto dun imperio americano digno do seu nome (Caughfield 2005; Kaplan i988). Non doutro xeito se podería entender o discurso sentimental e moralizante aplicado ás mulleres por ambos os dous sexos alén do Atlántico. En Europa a intención era limitar ou definir as oportunidades (ou falta delas) das mulleres. En troques, nos Estados Unidos os pensadores da patria procuraban construír un territorio cada vez máis amplo e apoiábanse no concepto do fogar para acadar o proxecto imperial. Pode parecer unha contradición, mais non o é: a moral relixiosa era tan forte na nova nación que o que podía facerse de portas para fóra tiña que basearse nos valores da familia — valores que a muller como dona e nai controlaba ou mantiña baixo o seu poder. A muller ideal, relixiosa, intelixente (e dócil, ímolo admitir) era a mellor para ser nai da patria, nai da familia internacional que o goberno dos Estados Unidos procuraba criar.

Pese ás súas arelas de expansión, a nova nación tiña desafíos. Dende a perspectiva feminina, e mais a relixiosa, había dous temas esenciais que precisaban un remedio para que fose a sociedade forte: o excesivo uso do alcol e a escravitude, referíndose esta á escravitude da raza africana (isto non quere dicir que non houbese homes da mesma opinión). O alcol resultaba problemático porque afectaba a economía e a saúde da familia, e así ameazaba a estabilidade do país. Os bébedos remataban no cárcere, bouraban na dona e nos fillos, non eran leais e, polo tanto, eran perigosos. Por riba non pagaban as débedas. Estragaban coa conduta errática a estrutura social, ou ameazaban con facelo (McCall 200I). Debía ser no mundo anglosaxón un asunto grave, porque se en Inglaterra máis dunha señora comezara a escribir novelas para manter a familia, ${ }^{3}$ nos Estados Unidos o chamado Temperance Movement non era só de natureza relixiosa ou puritana senón que xurdiu entre as mulleres por mor da autodefensa (McCall 200I).

${ }^{3}$ Sabemos dunha escritora inglesa, autora de 40 novelas, nai de varios fillos e dona dun home inútil, eterno residente no cárcere. 
A escravitude, xa se sabe, era comprendida polas mulleres, para as que a democracia non era automática nin de dereito. Vexamos a declaración de sentimentos de Seneca Falls de i848 en que, nunha reformulación da Declaración de Independencia dos Estados Unidos, as participantes afirman: «all men and women are created equal». ${ }^{4}$ Dende o fogar, as nais podían estabelecer, e estabelecían, unhas regras de conduta para a sociedade en xeral. Podían loitar contra o que consideraban a violencia e a brutalidade dos homes contrapóndoas con valores de amor e autosacrificio. Eran tácticas estratéxicas, non simple submisión feminina.

Aínda que tivese parámetros diferentes, unha novela feminina de Norteamérica podía ter interese para Rosalía de Castro, a galega que tamén arelaba ser escritora e se atopaba nuns círculos dominados por homes. Alén do Atlántico había moitas lectoras de novela e as autoras publicaban principalmente para elas. A profesión literaria, xunto coa de mestra, foi a máis popular, a mellor admitida pola sociedade. O primeiro best-seller foi The Wide, Wide World de Susan Warner (I8I9-1885), ${ }^{5}$ que saíu en i850. Malia a autora ser de orientación calvinista, relixión na cal o ser humano era considerado por natureza depravado, e estar a protagonista Ellen Montgomery máis interesada no éxito persoal, a novela de Warner é un exemplo do Bildungsroman feminino e mostra certa influencia da unitarista (e polo tanto, máis liberal) Catharine Maria

${ }^{4}$ Di a Declaration of Sentiments: «We hold these truths to be self-evident: that all men and women are created equal; that they are endowed by their Creator with certain inalienable rights; that among these are life, liberty, and the pursuit of happiness; that to secure these rights governments are instituted, deriving their just powers from the consent of the governed. Whenever any form of government becomes destructive of these ends, it is the right of those who suffer from it to refuse allegiance to it, and to insist upon the institution of a new government, laying its foundation on such principles, and organizing its powers in such form, as to them shall seem most likely to effect their safety and happiness. Prudence indeed, will dictate that governments long established should not be changed for light and transient causes and accordingly all experience hath shown that mankind are more disposed to suffer, while evils are sufferable, than to right themselves by abolishing the forms to which they were accustomed. But when a long train of abuses and usurpations, pursuing invariably the same object evinces a design to reduce them under absolute despotism, it is their duty to throw off such government, and to provide new guards for their future security. Such has been the patient sufferance of the women under this government, and such is now the necessity which constrains them to demand the equal station to which they are entitled» (Stanton et al. I848).

${ }^{5}$ Publicouse co pseudónimo de Elizabeth Wetherell (George P. Putnam, I851). Cf. a edición dixital en $<$ http://widewideworlddigitaledition.siue.edu/>. 
Sedgwick, cuxa obra A New-England Tale (1822) sería a primeira novela escrita por unha muller naquel país. ${ }^{6}$ Consideramos moi relevante o feito de que Maria Susanna Cummins chegase a coñecer a Sedgwick na Mrs. Charles Sedgwick's Young Ladies' School, ${ }^{7}$ en Lenox, Massachusetts. A novela de Sedgwick non é o primeiro caso de protagonista orfa, virtuosa, mais si que introduce, por primeira vez, a figura da tía inflexíbel, a antagonista falta de agarimo, que tamén vemos en Nan, na novela de Cummins.

En i852, Harriet Beecher Stowe publicaría Uncle Tom's Cabin e nos Estados Unidos as testemuñas do seu impacto inmediato abondan. Tería máis venda aínda a novela abolicionista de Stowe que a de Warner. En I854, The Lamplighter veu ocupar o segundo lugar de vendas nos Estados Unidos, non só de novela feminina, senón da novela en xeral. As traducións, ao francés, alemán, danés, italiano e outras linguas, non tardarían en aparecer. «What is the mystery of these innumerable editions of the Lamplighter?» protestaría Nathaniel Hawthorne (Baym 1985: 4) na carta xa aludida ao comezo. Ironicamente, o feito de ter moitos lectores, de ser a novela tan popular, foi unha pexa para que se considerase unha obra seria, de crítica social. Segundo a crítica Nina Baym, boa coñecedora da literatura feminina do XIX, The Lamplighter é máis progresista, concede un papel máis central e integrado para a protagonista na sociedade en que participa. Na súa función como Bildungsroman feminino, The Lamplighter non reflicte o fogar como espazo único nin ideal do seu sexo senón que analiza o ideal e o ter chegado a protagonista a ser, non só muller, senón adulta (o destacado é noso):

[the] women's version of the Bildungsroman is much concerned with the formation of character in the old-fashioned sense of strengthening within individuals particular traits that are deemed admirable. Chief among these are self-control and its near-relation, self-discipline. This typically Victorian emphasis, which may not seem attractive to late twentieth-century readers, stems from a belief that only the firmly organized and self-controlled character can act effectively. Though character formation along these lines is essential for both men and women, it is more important for women because, first, they must compensate for starting out in a much less powerful position than men, and, second, they must struggle against a strong cultural preference for women who are weak and vulnerable. (Baym I998: XI)

${ }^{6}$ Catharine Maria Sedgwick, nada e finada en Massachsetts (1789-1867). Tamén autora de: Hope Leslie (1827); Clarence, or, A Tale of Our Own Times (1830); Live and Let Live (I857), e outras obras.

${ }^{7}$ Escola do irmán, onde Sedgwick lía aos alunos. Non casou, algo non habitual daquela. 
Baym tamén teoriza que a obra de Cummins é unha americanización do mundo dickensiano, e explica que isto foi posíbel por mor do desenvolvemento dos espazos urbanos. Dentro da zona urbana de ${ }^{*} \mathrm{D}$ onde mora Gerty cando nova, e que se basea en Dorchester, a vila nos arrabaldes de Boston onde vivía a propia Cummins, o fogar ten certos valores fundamentais que representan a forza moral, non a fraqueza ou o estado indefenso. Malia ser pobre, cómpre ter un fogar limpo no material e no moral, porque así — cre a cultura protestante e, nalgúns casos, transcendentalista- pode xerar relacións humanas boas e xenerosas, cunha ética e un valor, pese á adversidade, que a xente rica non adoita ter. Por iso o nome do benfeitor de Gerty é Trueman Flint ${ }^{8}$ —indicio moi evidente da súa estatura moral e figura paterna perfecta para guiar o proceso de civilización polo que debe pasar a pequena rapaza medio-salvaxe. Non nos confundamos: o de «salvaxe» non é un risco totalmente negativo; na sociedade do self-made man isto é a fonte de enerxía e a vontade que ela precisa para acadar a súa transformación como muller de decisión. É dicir, que o de self-made non era só ideal masculino, senón que abranguía de certo modo as mulleres e considerábase un indicio de carácter, de forza, algo que todos precisaban se querían sobrevivir nun país que aínda non tiña fronteira cara ao oeste. Non esquezamos que o título do primeiro best-seller reflicte o ideal de expansión dun país que estaba a medrar. As mulleres tiñan que estar na fronteira, forxando mundo, tamén. Como sinala Gillian Avery (1989: 8):

Susan Warner, herself a powerful weeper, produced the greatest volume of tears — indeed Van Wyck Brooks called The Wide, Wide World « a swamp of lachrymosity » — but Cummins the noisiest weeping. Gerty « always cried aloud — not sobbing, as many children do, but uttering a succession of piercing shrieks, until she sometimes quite exhausted her strength».

A aparencia da orfa, fraca, malcriada, marxinal muda moito cando nos decatamos de que a rapaza non chora senón que berra. Pensemos no poema «A xustiza pola man» e mais na gaita que chora — mesmo pode chorar de rabia, como Gerty.

Tense observado que unha traxectoria como a de Gerty, sempre artellada a partir do fogar, podería semellarnos un círculo pechado, de non avance para a muller. De novo, a coñecida imaxe do anxo do fogar ao estilo de Patmore vainos

${ }^{8}$ «Home Leal Lasca», traducido literalmente. 
tentar como modelo para a protagonista. Porén, cómpre vermos o simbolismo do mundo familiar no contexto norteamericano. O chamado cult of domesticity [culto da domesticidade ou do fogar] ou a culture of sentiment [cultura do sentimento ou de bágoas] deberá verse tamén en contraste co alleo, co estranxeiro, o non nacional, o non americano, ou, simplemente, o «non noso». Dende esta perspectiva, o fogar adquire o simbolismo da nación, e aínda máis, da nación que medra e procura influír nos demais países. Vexamos, de novo, a análise desta relación que non é moi evidente ou que ten sido interpretada de xeito trabucado (o destacado é noso):

When we contrast the domestic sphere with the market or political realm, men and women inhabit a divided social terrain, but when we oppose the domestic to the foreign, men and women become national allies against the alien, and the determining division is not gender but racial demarcations of otherness. [...]

If domesticity plays a key role in imagining the nation as home, then women, positioned at the center of the home, play a major role in defining the contours of the nation and its shifting borders with the foreign. Those feminist critics and and historians whose work has been fundamental in charting the paradigm of separate spheres, however, have for the most part overlooked the relationship of domesticity to nationalism and imperialism (Kaplan 1988: 582).

O propósito de Rosalía en La hija del mar non é, xa que logo, apoiar o imperialismo. Mais a narradora afirma o estado desexábel e seica utópico da vida galega. É utópico precisamente porque as mulleres son libres, non escravas: o traballo manual e duro é digno e fai parte da vida compartida da comunidade. A mesma crítica da aristocracia e burguesía vémola na novela de Cummins. Gerty, como Teresa, non procura unha vida acomodada senón digna, cun traballo honesto, que lle permita ter autonomía. É un detalle de moita importancia e unha idea fundamental en ambas as dúas literatas.

Mais a guía moral dela é a cega Emily, quen lle ensina a «relixión do corazón» e isto pode semellar unha lección conservadora, de submisión feminina. Porén, a «relixión» non é a da igrexa ou do Reverendo Arnold, quen representa a autoridade tirana porque esixe a obediencia á figura paterna (o pai de Emily). Subliñemos isto: é precisamente á figura relixiosa, masculina, a quen a protagonista se opón, dicindo que ten dereito a un traballo de seu. Require certo tipo de público lector para percibir isto. Gerty non deixa de ter opinións de seu e o valor para defendelas, porque ela de feito baixará de categoría social por non acatar os desexos do pai de Emily. Nunha palabra: en The Lamplighter, a trama e o remate da novela indican que a vida burguesa da familia da cega 
Emily non asegura a felicidade nin dela nin da súa afillada Gerty. O pai, autoritario, representa o intento americano de imitar a vida sofisticada dos europeos e de escoller a moda do materialismo superficial, incluíndo a afección á roupa e ás actividades frívolas da súa clase. O materialismo superficial só merece o desprezo da autora, de xeito moi semellante ao que veremos tamén en El caballero de las botas azules. O desenlace da novela é positivo porque os valores non materialistas, se cadra os precapitalistas, predominan; coa amizade e a fidelidade ás persoas, non ao diñeiro, o perigo de desaparición do fogar humilde e agarimoso é vencido. Repitamos: neste tipo de fogar, a muller non é obrigada a sufrir a escravitude, en parte porque a oportunidade de estudar, de exercer unha profesión como a de profesora, non lle vai ser negada.

O contexto de La hija del mar non é urbano; porén, o fogar humilde e os valores de Teresa —o traballo, o amor, a fidelidade — son a base da súa vida. A cabana onde morará con Esperanza até a chegada do pirata que é o seu home será un espazo sagrado, que ninguén quere profanar (sagrado no senso de libre e construído polas mulleres, quer dicir). En troques, o retorno de Ansot ocasiona o traslado de nai e filla adoptiva a unha residencia aristocrática, financiada polas actividades do home pirata-empresario. A nova casa, o espazo do fogar, xa non se pode clasificar de fogar, non hai espazo para conviviren os habitantes. A conversa tornase ríxida, os xestos tamén. Non hai amor, esa «relixión do corazón», ${ }^{9}$ senón enfrontamento, ameaza, violencia. Cando Ansot racha coa vida que construíran as mulleres sen bens materiais, impóndolles a súa vontade, a moza Esperanza pérdese psicoloxicamente e convértese en obxecto de admiración, contemplada polo home que nin sequera se decata de que ela é a súa filla. Esperanza non pode continuar, dominada pola ollada masculina, encarcerada e sen a nai espiritual. Non participa nunha comunidade. Se callar, Rosalía comprendía isto, como literata galega.

O contexto de Maria Susanna Cummins era a cidade de Boston e polo tanto era urbano; o de Rosalía era a súa Galiza e polo tanto rural. Mais as novelas delas teñen en común: (I) os valores éticos das protagonistas; (2) o antimaterialismo; (3) a capacidade de ensinar e guiar dunha muller un pouco máis madura que fai o papel de nai sen selo polo sangue; (4) o desexo de elixiren as mulleres cal vai ser o seu fogar. Non esquezamos que Gerty é botada fóra da casa

${ }^{9}$ Hannah More, escritora e filósofa, escribiría Practical Piety, or, The Influence of religion of the heart on human conduct (I8II) e «Slavery, a Poem» (1788). Foi integrante do grupo de Bluestockings. Tamén é autora de Bas Bleu, or, Conversation (1787), que vén ser a descrición da vida das literatas. 
de Nan, que a maltrataba, porque a pequena se rebelou contra a crueldade da patroa, sabendo que ía rematar na rúa. A nena xa aprendera que era preferíbel estar sen teito a ter que vivir cunha muller capaz de matar un gatiño porque si.

Os catro temas que sinalamos poden ser interpretados dende a perspectiva conservadora do sentimentalismo como «cousa de mulleres» ou como parámetros para estabelecermos un eido de protagonismo feminino forte. É máis: a valoración do mundo sinxelo, idílico, non se fai axeitadamente se non se contrapón ao comportamento dos que pertencen ao poder. No século XIX, a expresión dos dereitos da muller tiña outro discurso; lembremos que só uns anos antes se celebrara o encontro das sufraxistas de Seneca Falls. Malia a súa importancia para a identidade da nación, o fogar non era o único eido de actividade das mulleres nos Estados Unidos (xa mencionamos a profesión de mestra ou profesora). Igualmente, na costa galega as mulleres terían o traballo da pesca; o máis valorado era a piedade, o respecto polos demais, a honestidade. Non esquezamos outra cousa: que as mulleres protestantes podían ser misioneiras. Sería un traballo de ideoloxía conservadora, por unha banda; e pola outra, as misioneiras viaxaban moito, e lonxe, algunhas delas non ían acompañadas de homes. Todo un cambio nos anteriores costumes da sociedade.

Ambas as dúas orelas do Atlántico, entón, ofrecíanlles ás mulleres diversas oportunidades de seren elas suxeito histórico, de faceren escoitar a súa voz e de influíren na sociedade en xeral, non só nos fillos e no fogar. Non nos debe confundir a proliferación de novelas, algunhas sen moito valor literario nin moitas ideas, feito que a mesma Rosalía criticaría na metanovela El caballero de las botas azules. A «saída á rúa» dun libro non era garante de calidade; a inglesa George Eliot criticaría a silly novel e tamén, se cadra pola mesma razón, o noivo da protagonista de The Wide, Wide World aconsellaríalle non ler ela novelas na súa ausencia. Mais o terse alagado de novelas o mundo anglosaxón tamén tería algo que ver coa demanda, polo simple feito de que (I) había moitos lectores/compradores de narrativa, e (2) o público estaba disposto a mercar as obras de autoría feminina (malia non apareceren inicialmente algunhas das novelas co nome da escritora, como pasou con The Lamplighter).

Queremos insistir brevemente nesa cantidade de novelas, vistas como floods, deluge, dun «exceso de auga». E iso porque non podemos deixar de sentirnos atraídos polo feito de ter empregado Rosalía a imaxe da filla do mar na súa primeira novela. Noutro traballo (March 1994) xa temos subliñado a descrición que fai a narradora de Teresa, a nai de Esperanza, como poeta. Apuntáramos daquela que a observación non é moi lóxica no contexto da costa ga- 
lega, para unha muller que nin sequera se sabe se é alfabeta e seguramente non vai ter libros na casa. Cómpre, nunha palabra, non interpretar o papel de poeta de xeito literal. Sen dúbida non sabemos explicar como chegaría a exercer de «poeta» Teresa nunha paraxe como a Costa da Morte de Galiza, mais como esquecer que ela garda os seus momentos creativos para cando anda soa ao pé do mar? Como esquecer a relación entre poesía-natureza-loucura que se conxuga en Teresa? É máis: os supostos discursos ou textos poéticos non son reproducidos no texto; só presenciamos a relación muller $\sim$ mar $\sim$ imaxinación literaria $\sim$ liberdade $\sim$ soidade e escoitamos a voz narrativa (que é feminina) que a cualifica de poeta. Non sabemos que tipo de versos produce Teresa e non sabemos sequera se ela escribe, xa que non se describe esa actividade — só lemos que lle é preciso camiñar polo borde do mar. Cando o retorno de Ansot atalla as sesións poéticas, afogando as palabras de Teresa e obrigándoa a fuxir, xa podemos ir pensando no verdadeiro significado da poesía desa muller. E da total ironía con que Rosalía fala dela.

Esperanza, pola contra, non é escritora — nin poeta nin novelista— mais ten voz, rexeita a crueldade que sente pola matanza dos peixes (lembremos de novo como Gerty reacciona cando Nan mata o gatiño) e sofre até tolear no «cárcere de amor» de Alberto Ansot, o pai que non sabe nin quere ser pai. Ao mesmo tempo, non deixa de ser inspiración para os demais, sen ter un aspecto físico forte nin —aparentemente- unha dimensión psicolóxica ou social máis do que o papel de filla agarimosa. É de feito a intervención de tres mulleres - Teresa, Angela e Candora - nun xesto compartido o que representa a salvación. Son elas as guías, a trindade da rapaza, as que permiten que ela fuxa e atope a liberdade no mar de onde veu. Non resulta totalmente claro quen — cal delas — se achega a rescatar o seu corpo sen vida na Praia do Rostro, mais o simbolismo do nome da rapaza ofrece unha orientación segura: Esperanza.

Libre xa da tiranía de Ansot, pode ser quen é en vez de exercer só como obxecto que existe unicamente para o pracer da ollada masculina. Escolle a liberdade da mar, coñecida dende os tempos antigos como elemento ou espazo feminino, vasto, acompañada das súas «ondas irmás» (palabras dela mesma). É o mar de Esperanza, un mar de esperanza, de porvir, non o dos piratas depredadores. É máis: a decisión de incorporarse ao mar non é símbolo de fracaso senón de vitoria da vontade da muller. É o novo fogar para a Eva Nova (Taylor 1993), mal comprendido como suicidio e polo tanto, o fracaso da rapaza, pola crítica anterior. É o sentimento, non a emoción choromiqueira dos fracos e medorentos, senón a paixón dos sobreviventes por experimentar a vida. 
A produción e popularidade da literatura sentimental non foi, dixemos ao comezo, mostra de submisión; representaba o xeito en que ás veces as mulleres podían, e inclusive esixían, ocupar un lugar público, aínda que fose por mor dun disfrace ou afastándose do podio autorial coa publicación anónima. Lembremos, máis unha vez, que a relixión tiña unha función liberadora nos Estados Unidos:

It was a truism of Protestant ideology that the invention of the printing press made possible the religious and political enfranchisement of previously subjugated peoples. As well as consuming print products, women quickly moved to position themselves as producers. They argued successfully that print's invisibility, which allowed ideas to circulate independently of the bodies that created them, freed women from their sexualized identities and thus gave them a better chance to achieve parity with men (Baym I998: 339). ${ }^{10}$

Rosalía de Castro non viviu nunha sociedade protestante, mais as súas protagonistas arelaban unha liberdade de movemento e expresión igual que as anglofalantes. A muller galega da costa seica non tería a oportunidade (que tiveron Cummins, Stowe e outras) de participar nun grupo de literatas, nin tería tanto aceso aos estudos, mais non o terían tampouco os homes da zona rural. Ao mesmo tempo, tivo, como Teresa, a capacidade de pensar e crear e valeuse, como fixera a súa filla adoptiva, da colaboración feminina — neste caso, a colaboración de Teresa con Candora e Angela- para asegurar o futuro dunha Esperanza en liberdade.

\section{REFERENCIAS BIBLIOGRÁFICAS}

Avery, Gillian (1989). «"Remarkable and Winning": A Hundred Years of American Heroines». The Lion and the Unicorn, I3:I (xuño), 7-20.

Baym, Nina (1985). «Rewriting the Scribbling Women». Legacy, 2:2 (Fall), 3-12.

BAym, Nina (1988). «Introduction». The Lamplighter. New Brunswick, NJ: Rutgers University Press, IX-Xxxv.

${ }^{10}$ Non foi, porén, doado. Houbo mulleres editoras, xornalistas e novelistas, mais como temos visto noutros estudos (March 1994), Fanny Fern loitou contra pai, irmán e mais o home para ser literata. O prezo foi alto, como vemos na súa novela autobiográfica, Ruth Hall (1855). Ver Harris (1990) e Wood (1971). 
BAYm, Nina (1998). «Women's Novels and Women's Minds: An Unsentimental View of Nineteenth-Century American Women's Fiction». NOVEL: A Forum on Fiction, 3I:3, Thirtieth Anniversary Issue: III (verán), 335-350.

Caughfield, Adrienne (2005). True Women and Westward Expansion. College Station, TX: Texas A\&M University Press.

Frederick, John T. (1975). «Hawthorne's Scribbling Women». The New England Quarterly, 48:2 (xuño), 23I-240.

Harris, Susan K. (1990). «Inscribing and Defining: The Many Voices of Fanny Fern's Ruth Hall». Nineteenth-Century American Women's Novels: Interpretative Strategies. Cambridge, U.K.: Cambridge University Press, III-27.

Kaplan, Amy (1988). «Manifest Domesticity». American Literature, I0:3 (set.), 58I606.

Kelley, Mary (200I). Private Woman, Public Stage: Literary Domesticity in NineteenthCentury America. Chapel Hill, NC: University of North Carolina Press.

March, Kathleen N. (1994). De musa a literata: El feminismo en la narrativa de Rosalía de Castro. Sada: Ediciós do Castro.

McCall, Laura (200I). «Shall I Fetter Her Will? Literary Americans Confront Feminine Submission, I820-1870». Journal of the Early Republic, 21:I (primavera), 95II3.

Peterson, M. Jeanne (1984). «No Angels in the House: The Victorian Myth and the Paget Women». The American Historical Review, 89:3 (xuño), 677-708.

Rabinovitch, Eyal (200I). «Gender and the Public Sphere: Alternative Forms of Integration in Nineteenth-Century America». Sociological Theory, 19:3 (nov.), 344370 .

Stanton, Elizabeth Candy et al. (i848). Declaration of Sentiments. [En liña] [6 xuño 20I3]. <http://www.library.csi.cuny.edu/dept/americanstudies/lavender/decsent2. html>.

TAYLOR, Barbara (1993). Eve and the New Jerusalem: Socialism and Feminism in the Nineteenth Century. Cambridge, MA: Harvard UP.

Voloshin, Beverly R. (1984) «The Limits of Domesticity: The Female Bildungsroman in America, 1820-1870». Woman's Studies, 10, 283-302.

Wallace, James D. (I990). «Hawthorne and the Scribbling Women Reconsidered». American Literature (xuño), 20I-222.

Wood, Ann D. (197I). «The 'Scribbling Women' and Fanny Fern: Why Women Wrote». American Quarterly, 23:I (primavera), 3-24. 